\title{
Internship Programs for Undergraduate Health Informatics Students in Saudi Arabia
}

\section{Saleh Altuwayrib ( $\nabla$ s.292@hotmail.com )}

University of Hail https://orcid.org/0000-0002-6148-9546

\section{Khin Than Win}

University of Wollongong Faculty of Engineering and Information Sciences

\section{Research article}

Keywords: health informatics, internship, students, education, undergraduate, Saudi Arabia

Posted Date: November 13th, 2019

DOI: https://doi.org/10.21203/rs.2.17215/v1

License: (9) This work is licensed under a Creative Commons Attribution 4.0 International License. Read Full License 


\section{Internship Programs for Undergraduate Health Informatics Students in Saudi Arabia}

\section{Saleh A. Altuwayrib,}

Department of Health informatics,

Public health and Health informatics college - University of Hail, Saudi Arabia.

\section{s.292@hotmail.com}

$+966541960001$

\section{Associate Professor, Khin Than Win}

School of Computing and Information Technology

Faculty of Engineering and Information Sciences - University of Wollongong, Australia win@uow.edu.au

$+61242214142$

\section{Highlights}

- Internship programs have a positive impact on students' skills and provide students with non-monetary incentives

- Academic institutions should consider the selection criteria of internship sites

- There is a need to investigate the linkage between health informatics education outcomes and Saudi labour market needs.

- There is a need for well-defined structure of health informatics internship program and competencies framework. 


\section{Internship Programs for Undergraduate Health Informatics Students in Saudi Arabia}

\section{Abstract \\ Background}

Internship program is one of the experiential learning methods that enable students to gain practicum experience and learn from specialised people. This type of learning is a professional gateway to integrate knowledge with practical application. This study defines the state of health informatics internship programs in Saudi Arabia and examines the difference between interns and graduated students' perceptions about the experience of health informatics internship programs in Saudi hospitals.

\section{Methods}

An online survey was constructed and distributed to health informatics students through social media platforms and specialised groups. The sample size included 89 participants from different universities across Saudi Arabia regions.

\section{Results}

The findings indicate that the majority of participants believe that internship programs have a positive impact on students' skills and provide students with non-monetary incentives. ANOVA analysis and t-test results indicated that there is no significance difference between the interns and graduates perceptions ( $p$-value 0.495 , alpha value 0.005 )

\section{Conclusion}

Health informatics internship programs in the Kingdom should consider some aspects: the selection criteria of internship sites, the linkage between education outcomes and Saudi labour market needs, effective experiential learning methods, well-defined structure of health informatics internship program and competencies framework.

Keywords: health informatics, internship, students, education, undergraduate, Saudi Arabia. 


\section{Background}

Biomedical and health informatics evolution have been comparatively younger than other disciplines. Education plays a major role in the advancement of this discipline. Several programs, both undergraduate and postgraduate, have been developed to train health informaticians. The International Medical Informatics Association (IMIA) has also developed recommendations for health informatics education. Health informatics education programs provide a new generation of qualified informaticians who can manage and support health informatics applications in health care settings and academic research [1]. Health informaticians should have a clear interdisciplinary understanding of their field while being equipped with integrated knowledge and competencies in health sciences, healthcare systems, ICT and management [2]. The provision of health informatics education programs is affected by the association between academic institutions and health care organisations. Health informatics training programs are usually associated with acquiring skills in using or implementing health information systems $[3,4]$. Health informatics training is an educational method that enables the students to use or implement health information systems, such as an Electronic Medical Record (EMR) system, Hospital Information Systems, and other health information technologies [4]. Adequate training with solid methodology could be a successful indicator of the implementation of various health information systems [5] and the application of technology in healthcare. Internships provide students with work experience that enables them to apply the knowledge acquired in classrooms to the workplace $[6,7]$. This type of learning is known as experiential learning, in which the intern learns from the work experience. Experiential learning is a process that depends on participation, interaction and application. Such a process allows learners to interact with their environment and expose them to diverse tasks that vary from simple to complex. Experiential learning engages the learners in learning processes which may affect their cognitive and behavioural dimensions [8]. The characteristics of experiential learning include a continuous and comprehensive learning process based on real-world experience and a process of knowledge creation and communication channels establishment between an individual and the learning environment. An educational program that can apply these characteristics is able to cover a large number of skills and traits that are essential in the professional environment [9]. Experiential learning theory, developed by David A. Kolb in 
1984, has been adopted for internship programs throughout North America by many colleges and universities [6].

\subsection{Knowledge and Practical Experience}

The internship experience enables interns to bridge theoretical knowledge with the professional practise $[6,10]$. This experience helps students to understand the work environment better and solidify concepts that were learned in university $[6,9,11]$. It allows students and their faculty to access the latest adopted technologies in the industry, enabling them to use the workplace as an extension of the tutorial rooms. This provides university students with real-world experience, which can foster positive motivation and create good relationships between the university and the business entities [9]. Furthermore, the internship stimulates student's interest in learning and expands educational opportunities for learners through experiential learning programs [6]. The experiential learning theory is a learning theory that could be applicable to internship programs which describes learning processes as consisting of four stages which include: the experience design, observe, conceptualise and test [6]. Additionally, purposeful learning experience involving building effective conditions enables learners to link hands-on practical experience to learning goals through harmonising the four learning stages. Thus, experiential learning theory is comprehensive in nature because of its emphasis on emotional, insightful, cognitive, and behavioural aspects of students [8, 12]. Internship programs can provide valuable experience for students, but the lack of proper structure may lead to "highly variable learning" resulting from the poor structure of experience design or the lack of process feedback [8]. Failing to address each stage in the learning process may lead to challenges in the ability to build suitable conditions for effective learning [6]. Students need to evaluate the experience and to receive feedback from the instructor using criteria that can help in assessing students' ability to learn from the experience.

\subsection{Soft Skills}

Soft skills are a set of personal qualities and interpersonal skills that help to engage and communicate effectively within the work environment [13-15], whereas, hard skills are a set of academic and technical skills that can be learned and tested in academic institutions [15]. Hard skills include reading, writing, programming, and the ability to use computer programs [13]. On the other hand, soft skills include communication, flexibility, creativity, 
motivation, critical thinking, persuasion, problem-solving, teamwork, time management and work ethic [14]. Problem-solving is the ability of an individual to define the source of a problem and devise an appropriate solution. Health informatics specialists work with multidisciplinary health professionals to improve health care processes, and this requires deep understanding and an ability to solve problems [16]. Communication is another important soft skill that enables a person to transfer and share information with others in different forms. Health informatics projects deal with big and complex health data which require the ability to communicate effectively within interdisciplinary teamwork and with others. Interpersonal skills are defined as the ability to interact with other people effectively [16]. Internship exposes students to work experience that could empower them to develop their skills and improve their confidence in the field [9].

\subsection{The Benefits of Internship Programs}

Internship programs provide many benefits not only for students but also for universities and training organisations [6]. Also, Internship programs provide students with the opportunity to experience the necessary job fields. Students can, therefore, decide early about their career path after their graduation. This experience helps students with high academic performance to find good jobs. After completing the internship experience, students can enter the professional environment with more confidence, maturity and selfreliance while having the necessary social skills [9]. After graduation, students appreciate the benefits of internship work experience that help them to face the relevant work requirements. The internship experience and updated knowledge of the field should enable students to be more skilled and confident during job interviews which usually leads skilled interns to obtain good job offers. Internships support students to improve a sense of selfefficacy, which is the individuals' judgments about their competences when they execute a series of tasks that are required to achieve particular performance [9]. The following are other benefits for students:

- $\quad$ real-world experience [6]

- $\quad$ improving the awareness of professional values and ethical issues $[6,10]$

- $\quad$ increasing employment opportunities $[6,17]$

- $\quad$ empowering them to create a professional network $[6,18]$

- $\quad$ increasing their employment probability after graduation $[6,17]$. 
The following are academic institutional benefits of the internship programs:

- $\quad$ developing high competencies [6]

- improving communication with the organisations in the industry $[6,9,10]$

- gaining opportunities to identify curriculum issues, and thus enabling them to improve their programs $[6,11,18,19]$

- $\quad$ enhancing student recruitment $[6,9]$

- $\quad$ achieving a notable reputation [6].

In addition, internship sites can gain many advantages from internship programs which include:

- $\quad$ accessing students with high competencies for temporary employment $[6,9]$

- $\quad$ accessing students with recent academic knowledge in the industry field $[6,9]$

- $\quad$ obtaining the perspective of a younger generation [6]

- improving the employees' retention rate $[9,10]$

- $\quad$ offering an opportunity to select skilled and knowledgeable employees with a fresh perspective $[6,9,18]$

- $\quad$ providing an opportunity to contribute to the community and improve social responsibility $[10,18]$

- enabling professional staff to develop creative and advanced projects [10]

- $\quad$ strengthening organisations partnership with academic institutions [9]

- $\quad$ supporting organisations to implement the latest strategies and techniques $[10]$.

There are many potential benefits for all involved parties in an internship program, but it is essential to consider the method in which these programs are designed and implemented. Internship programs are also important for all involved parties to improve the partnership between education providers and organisations in the industry, thus providing students with opportunities for career preparation. Also, this partnership enables students to build a strong curriculum vitae and organisations to develop new ideas influenced by interns who learned recent knowledge or techniques in the field. To achieve these benefits, it is important to consider many factors that relate to student satisfaction with the internship program. Such factors include financial issues, the suitability of program location, duration 
of the program, ability to develop a professional network, ability to complete assigned tasks, ability to obtain feedback from professionals and hands-on experience. Students, therefore, expect an internship program to be experiential learning and to support their professional development through hands-on experience and exposing them to a variety of areas in the field. Despite these benefits, many concerns arise about the learning quality in internship programs, legal and ethical issues and timing of internship programs $[6,11,18]$. In conclusion, internship programs affect interns' knowledge and skills and provide them with non-monetary incentives and necessary experiences that help them in future employment. Bakar et al. [16], Muhamad et al. [20], and True [11] also studied benefits of internship program in different industries such as accounting and tourism.

\subsection{Health Information Systems and Internship Program}

The use of health information systems is instrumental for informatics students and other health speciality students [21-23]. An example of one of health informatics applications is an EMR, which is defined as "an electronic record related to patient health that enables healthcare organisations to create, collect and manage health information by using advanced capabilities and improving the accessibility of authorised health care providers and staff" [24]. Borycki et al. [25] measured health informatics students' competencies in different aspects: information management, health science and management related to health informatics and the Canadian health system. The results showed that hands-on exposure to EMR systems improves participants' competencies and ability to reduce errors and information redundancies [25]. Also, Gibson et al. [21] found that pharmacy student confidence and their navigation of EMR are improved using a simulated EMR. Additionally, students' ability to learn, extraction of meaningful health data from the system, and understanding of health informatics role in patient care are all improved using this kind of experiential learning [21]. Similarly, Choi et al. [23] recommended that nursing education should integrate the use of EMR system in the clinical practicum to prepare nursing students with required competencies because of limited opportunities to use these systems in clinical settings [23]. George [22] also noted that nursing student's exposure to a simulated EMR significantly enhance the navigation time and retain the accuracy level and supported students to move from beginner to competent level [22]. Sapci and Sapci [26] conducted a study to examine the effects of new innovative health informatics laboratories. The quantitative data showed that $95 \%$ of students were interested in taking more experiential 
health informatics courses, $75 \%$ agreed that system exposure had improved their confidence to train patients to use wireless patient monitoring devices, and $90 \%$ of students found the experiential approach to be useful and were interested in joining a similar learning experience. More than $50 \%$ of the participants did not have prior experience with topics such as health image, health data collection and storage and communication protocols [26]. Likewise, health informatics students' exposure to health information systems within the health care environment is considered as a critical issue [3].

\subsection{Electronic medical record in health informatics education:}

There are many challenges that limit the integration of the EMR into health education which include the shortage of qualified academic professionals who are familiar with using different educational EMR systems, the scarcity of qualified health informaticians who are able to implement these systems effectively, and the lack of opportunities to access different types of educational EMR systems. Students should use different types of EMR systems and learn how these systems can be implemented in different health organisations. Thus, internship programs are aimed to understand the variability of terminologies and processes from one organisation to another, and how health informaticians can adapt health professional tasks to the technology within health care organisations. This knowledge will help students to understand the capabilities and limitations of EMR systems and this will enable them to predict the potential risks and opportunities associated with the current system [27]. However, the level of EMR adoption is directly proportional to the degree of organisation's ability to complete the levels of implementation, maintenance, and improvements for the existing system [28]. In the US, the adoption rate of EMR in teaching hospitals is higher than in non-teaching hospitals [29]. Health organisations that try to adopt EMR systems may encounter many challenges such as cost, security and change resistance. Although adopting EMR systems provides health organisations with many benefits including enhancing quality and efficiency of hospital services and improving the communication between health professionals and other organisations (e.g., reducing rejected insurance claims and unpaid services) [29].

One of the most popular tools used to measure the EMR adoption level in health organisations is the EMR Adoption Model, which was created by The Healthcare Information and Management Systems Society (HIMSS) Analytics group in 2005 [30]. The Healthcare 
Information and Management Systems Society has established EMR adoption model that identifies the EMR capabilities from (Stage 0 to Stage 7) which starts from implementing simple capabilities such as some automation ancillary departments, and complex capabilities such as Clinic Decision Support Systems (CDSS), and Clinical Physician Order Entry as shown in Figure 1 [31].

Bah \& Alanzi found that hospitals which develop their own Electronic Health Record (EHR) are more convenient for students training compared with the hospitals which adopt commercial EHR because health informatics interns can use the system and be involved in its development during their rotation. While hospitals with commercial EHR systems are managed by technical staffs associated with the software vendor and this limit interns' exposure and engagement with health information systems during their rotation. Also, if the information technology (IT) department is very busy managing and implementing changes to the system, an appropriate selection of training setting has a positive impact on students' knowledge and competencies and provide students with opportunities in terms of employment. In contrast, inappropriate selection of training setting may negatively impact trainees' skills, self-confidence and future employment opportunities. Additionally, Interns' reports can provide comprehensive information about the training situation, thus enabling the training administration to understand students' expectations and evaluate the current situation of training. This facilitates supporting decision-makers by studying the feasibility of different training locations [32].

\subsection{Health Informatics Internship in Saudi Arabia}

Universities that offer health informatics and information management/system educational programs have been affected by the variability of health informatics speciality naming. The internship program is required by all universities that offer Bachelor of Health Informatics [33]. There are seven health informatics educational programs that are offered in seven governmental universities in Saudi Arabia. Each program has a different name, and these programs are classified into two groups which are health informatics programs and health information management and information technology programs [33]. Health informatics education contributes in developing health informatics profession, but there is a lack of available information about the number of graduated health informaticians, their job titles, positions, and the future need of health informaticians in Saudi Arabia [34]. Health 
informatics programs outcomes need to be conformed to national and international standards; for example, the recommendations of the IMIA for health informatics learning outcomes in terms of knowledge and skills within the health care industry. Students should have integrated knowledge and skills in areas that include core health informatics knowledge and skills, health sciences and information science [35]. This classification provides the main sciences related to health informatics and the required level of knowledge and skills in each field, which can help in assessing health informatics educational programs and comparing program structures among different academic institutions [35]. In Saudi Arabia, around 60\% of the hospitals are funded by the Ministry of Health $(\mathrm{MOH})$, but insufficient initiatives have so far been made by $\mathrm{MOH}$ to develop and implement e-health applications within their hospitals [36]. Previous studies show that EHR adoption rate in Saudi Arabia is increasing while the number of hospitals that adopt EHR systems is unexplored. According to Aldosari [28], only $50 \%$ of hospitals have adopted EHR in Riyadh city, $36 \%$ working on system implementation, and just $14 \%$ of hospitals did not adopt EHR. In the eastern region of Saudi Arabia, out of 19 hospitals, only three hospitals have adopted EHR [28]. Therefore, the role of health informatics speciality within the healthcare industry in the Kingdom is still not well recognised, and health informatics education programs face many obstacles in terms of structuring training programs. These issues are caused by the ambiguity of health informatics roles in health care settings and academia [34]. This ambiguity could create many challenges for health informatics interns in regional hospitals $[33,36]$. From a practical perspective, the learning outcomes of health informatics education and training programs should be perfectly linked to health informaticians' roles, responsibilities, and positions [37]. To achieve health care transformation that is considered as one of the main components of Saudi 2030 vision, health care sector is expected to be affected by the proposed changes by 2020 . According to the National Transformation Program 2020 (NTP), the third strategic objective of $\mathrm{MOH}$ is to achieve the digital transformation and optimum utilisation of information technology resources. The fourth strategic objective is to improve training and professional development, both nationally and globally, by providing individuals with sufficient knowledge and skills to meet future labour market demands [38]. Furthermore, the education sector has a strategic objective aimed at improving the educational institutions' capabilities to manage the nationwide developmental requirements and ensuring that 
education outcomes meet the market demands [39]. This begs the question: are Saudi hospitals able to provide health informatics students with relevant internship experience? Moreover, there is little literature about Saudi health informatics education programs, especially in the area of internship programs. This question and the gap in literature motivated the researcher to study the current state of health informatics internship programs in Saudi Arabia and to assess interns' perceptions on the experience of these internship programs in Saudi hospitals.

\section{Method}

This study adopted a quantitative research method to collect, manipulate and interpret quantitative data about health informatics internship programs in Saudi Arabia. A survey instrument was used in this study as a tool to collect quantitative data about interns' perceptions of health informatics internship programs in Saudi regional hospitals. There was only one previously published study about health informatics internship programs in Saudi Arabia [31], and it was conducted specifically for one health informatics education program. Therefore, a gap in past and current research was identified: 'the need to define the current situation of health informatics internship programs in Saudi Arabia.'

\subsection{Data Collection and Analysis}

The questionnaire was distributed to interns and graduated students of health informatics in Saudi universities using social media networks to access the target group. The questionnaire's first part includes demographic information about the student status, internship site, internship program duration, university name, gender, GPA (grade point average) and the department responsible for training the student. The second part contains 17 statements which are classified into four sections: career, knowledge and practical experience, skills and non-monetary incentives. Each section contains a set of statements that will enable participants to express their opinions through agreement or disagreement. The 17 statements measured using a 5-point Likert scale which includes: strongly agree, agree, neutral, disagree and strongly disagree. The questionnaire's third part contains three questions, which can be answered by yes or no, to examine students' satisfaction on the internship experience, and their perceptions about the structure and objectives of internship program. The last part is an open-ended question about students' suggestions for the internship program. The survey form was developed using SurveyMonkey, and the 
survey link was shared via social media platforms such as Twitter and Facebook using tags related to health informatics field in Arabic and English (e.g. \#Health_informatics) to attract interested students in Saudi Arabia. The survey was also shared with specialised professional groups that have student members or members who can share the survey with students by contacting the group administrators (e.g., Saudi e-health group and Saudi informaticians). Ethics approval for this study was granted by the Human Research Ethics Committee of the University of Wollongong (approval number 2018/416).

\section{Results}

This section provides information about the survey results which show participants' characteristics, perceptions, satisfaction and suggestions about the internship experience and programs structure.

\subsection{Participants' Characteristics:}

The number of participants was 89 students; $46 \%$ were males, and $54 \%$ were females. The female group consisted mainly of intern students, while the male group consisted mainly of graduated students. More than half of participants were interns (51\%), and the rest were graduated students (49\%). All participants experienced internship programs in Saudi hospitals, and the number of hospitals that host health informatics internship programs was 27 health care institutions across different regions in the Kingdom. About $80 \%$ of participants were enrolled or graduated from health informatics programs, and the other $20 \%$ of them were from the health information management programs. Most students had good performance in their studies, with $65 \%$ of them earning GPAs between 2.71 and 3.85 out of 4 and $28 \%$ of participants scoring between 1.57 and 2.70 . On average, $66 \%$ of health informatics educational programs provided students with the opportunity to experience internship programs in health informatics departments, whereas, the percentage for health information management and information technology programs was 52\% (Table 1).

\subsection{Participants' Perceptions}

The survey has four sections. Overall, the highest average of the agreement for both intern and graduated students was in the soft skills section and the non-monetary incentives section. The lowest average of the agreement for both intern and graduated students was in the knowledge and practical experience section (Table 2). 


\subsubsection{Career}

The results show that most of the participants, either intern or graduated students, agree that "an internship programme will provide them with the necessary information and experiences to choose the right career path upon graduation." The lower agreement statement for both intern and graduated students was about "the ability of internship programme to provide them with a better understanding of health informaticians' roles and responsibilities in hospitals."

\subsubsection{Knowledge and practical experience}

The participants were asked about the ability of internship experience to link what interns have learned in the university with the work environment. The results indicate that most interns believe that the internship experience can expose them to the latest technology adopted in the workplace. Moreover, intern students who have spent three to six months in their internship have a higher level of agreement about knowledge and practical section compared with other interns who spend more than six months or less than three months. About $60 \%$ of intern students disagree about the statement the internship experiences make educational experiences more relevant to their field.' While most graduated students believe that internship experience will reinforce the knowledge they gained in the classroom, a large number of them disagree about the ability of internship experience to expose them to the latest technologies adopted in the workplace. Therefore, students who were trained in health informatics departments have a higher level of agreement (63\%) in the knowledge and practical section compared with other students trained in other departments (57\%; e.g., IT, information management). Also, in departments that are not related to health informatics, the level of agreement was $48 \%$.

\subsubsection{Soft skills}

This section of the survey was aimed to find out participants opinions regarding the ability of internship programs to improve student skills in terms of problem-solving, communication and interpersonal skills. It was also aimed to explore the program's ability to build students' self-confidence and improve their English language. This section has earned the highest level of agreement in comparison to other sections (of which the average was 3.67). A big proportion of participants have an agreement about the statement 'the 
internship experiences will help them to improve personal confidence and self-esteem.' While most participants disagree about "the internship programme will improve student English language." Additionally, interns who have spent three to six months have a higher level of agreement about soft skills section statements compared with other participants. Students who were trained in departments not related to health informatics have the highest level of agreement about the skills sections compared with participants who trained in departments related to health informatics.

\subsubsection{Incentives}

This section was focused on how the internship program can help interns build professional networks, teamwork and obtain feedback from the trainers about their progress. A large number of participants agree that the internship programme can give students the opportunity to work in a team, build professional networks and obtain feedback from the supervisor about their progress.

Furthermore, the difference in opinion between interns and graduated students were assessed by comparing the average of each statement between the two groups and a scatter graph was used to show the convergence of perceptions between the two groups as shown in (Figure 2). After ANOVA analysis and t-test were conducted (Table 2), It can be concluded that there is no significant difference between an intern and graduated students' perceptions by comparing the $p$-value 0.495 with an alpha value which was 0.005 for all the statements.

\subsection{Satisfaction and Program Structure}

The results reveal that almost half the participants (49\%) are satisfied with their internship experience. They were asked about the structure of internship programs; $63 \%$ believe that the internship program structure was not clear. Similarly, $49 \%$ of participants believe that internship programs help them in clarifying their professional interests and goals.

\subsection{Suggestions}

Qualitative analysis was conducted on the free text entered as suggestions. Six themes could be identified from the suggestions which revolved around the program structure, internship site, supervisors, curriculum, training methods and health professionals' awareness about the field of health informatics. 
The first aspect is the internship site. The majority of participants believe that the process of internship site selection needs to be improved. It is important to select hospitals that have health informatics departments and mature systems which are implemented according to the national and the international standards. Many participants mentioned that some of the hospitals had used health informatics interns to cover the shortage in other employees or to perform random tasks that are not related to health informaticians' roles.

"Universities should find internship sites who have implemented health informatics applications in the right way. "

"Training in hospitals who have "CBAHI accreditation" to ensure that organisation work according to the standards and have ability to train health informatics students ..."

"Select hospitals that have 500 beds and more, work language is English, who have electronic information system and distribute the program to cover all departments that relevant to health informatics department."

The second aspect relates to supervisors. Participants suggest that health informatics trainers in hospitals should have sufficient knowledge and skills related to the health informatics field. This could help interns to receive relevant knowledge and skills which supported with explicit roles and responsibilities that help them to determine their future interest.

"The supervisor shall be specialised in health informatics to give the trainees appropriate departments and tasks ...."

"The supervisor should be HI professional in order to keep the work guidelines more correct." "Inform the supervisors by the training facility to explain to the trainee the tasks and role of each department, ... and test the trainee at the end of the training period, ... give free courses for the trainees in computer, English language and communication skills".

The third aspect is about the internship programs structure. Participants suggest that health informatics internship programs should improve student technical skills in programming, application management and data analytics by using anonymous health data. Additionally, an internship should provide interns with relevant knowledge to extend what students have 
learned in classrooms, enabling them to experience the work environment in health informatics departments.

"There should be specialised trainers in universities and hospitals to enable students to properly link information, comprehension and understanding of health informatics specialisation."

"Apply what we have learned in the university !!"

"They should teach us something about health informatics ..."

The fourth aspect is about the awareness of health informatics speciality between health professionals in hospitals. Many participants suggest that there is a need to define health informaticians' roles and responsibilities within hospitals and illustrate the importance of health informatics field for health care organisations through educating administrative staff and health care professionals.

"Educate health care managers and professionals about health informatics speciality because now we just have training in receptions."

"Only we need to work as a health informatics specialist, not in the reception and as you know, that is not our profession."

"The role and value of health informaticians should be defined through courses and lectures because what we found in the hospitals is ignoring our specialisation..."

The fifth aspect is about training methods. Participants believe that training methods should be diverse to provide students with the required knowledge and improve their skills in technological aspects. Internship program tasks should be designed to cover health informaticians' roles and responsibilities.

"Some hospitals do not allow students to experience the system, only they explain the system theoretically, ... it preferred to give the students ten cases, and the student tries to solve it".

The sixth aspect is about the curriculum. A number of participants suggest the need of curricula improvements by academic institutions, which would ensure that students 
equipped with sufficient knowledge and skills that are compatible with the real work environment.

"Almost complete difference between the curriculum and the real work!!"

"Improve the curriculum first and then listen to students' suggestions."

\section{Discussion}

This study recognized academic institutions that provide health informatics educations programs as well as hosting organisations that offer health informatics internship programs in Saudi hospitals. The findings can help health informatics researchers to realise the current state of internship programs and departments where health informatics interns can train. Additionally, health informatics students and researchers in Saudi Arabia will be provided with a list of hospitals that offered internship programs in different regions across the Kingdom (see Table 4 in the appendices). This study also examines whether there are any differences in perceptions between interns and graduated students. The results show no significant difference between the two groups perceptions. Interestingly, both groups have high levels of agreement that internship programs can help students to improve their skills and provide them with more incentives. Furthermore, there is a low level of agreement in the perceptions about internship programs' ability to improve student knowledge and practical experience between graduated students. In contrast, the interns have a low level of agreement about the ability of internship programs to prepare them for future career. Therefore, the internship experiences have a positive impact on student skills as it provides them with more incentives, but it needs to provide interns with relevant knowledge and practical experience that prepares them for future career and helps them to determine their professional interest. The experiential learning programs should be designed to reinforce different skills to improve students' confidence, social interaction, ability to work with a team, and creativity $[6,9,10]$. The majority of Saudi health informatics interns believe that internship programs help them to be more confident, engaged and responsible. This explains why half the participants are satisfied with the internship programs in Saudi hospitals. However, $63 \%$ of participants believe that the internship programs' structure is not clear, and the program objectives are not clearly stated. Hence, there is a high level of disagreement among participants about the ability of current health informatics internship programs to provide interns with a clear understanding of health informaticians' roles and 
responsibilities. Furthermore, participants' suggestions are consistent with the previous studies [3,37] about the need to clarify the health informatics interns' roles and responsibilities and ensure that internship activities are linked to their roles $[33,36]$. This agreement confirms the need for the collaboration between academic institutions and the Saudi health care sector in order to build health informatics competencies framework to serve both health informatics specialists and interns $[1,40]$. To support the recognition of health informatics profession, there is a need for a robust collaboration between health informatics departments in academic institutions and health organisations [1,34]. The internship programs should provide interns with relevant experience to improve their understanding of the applications of health informatics and how these applications are managed within healthcare settings [18]. This can be achieved by exposing interns to health information systems (e.g., EHR and CDSSs) and enabling them to practice data quality and management principles by using anonymous health data [4,37]. Consequently, a third of the participants believed that health informatics education programs need to improve the selection criteria of hospitals that provide internship programs. Health informatics internship programs should be implemented in hospitals that adopt health information technologies while having qualified trainers. These trainers should be able to provide interns with relevant tasks and improve student's knowledge about the role of health informatics departments within health care industry. The level of EHR adoption could be used as an indicator of suitable health informatics internship sites. In Saudi Arabia, 15 hospitals were rewarded with HIMSS Stage 6 and thus were recommended as training centres for health informatics educational programs students (see Table 5 in the appendices) [30]. The appropriate selection of internship sites has a positive effect on interns' knowledge and skills, as it provides interns with more future career opportunities [32]. Furthermore, academic institutions, health care organisations and health informatics associations should form a strategic alliance to improve health informatics education programs and fill the gap between education outcomes and market demands in the Saudi health informatics industry. This can be achieved through enhanced internship programs that can be considered as a professional gateway for students. This will help the education sector to achieve the objectives of Saudi 2030 vision that aim to align educational outcomes with market demand. Moreover, this will help education programs to achieve the international recommendations on health informatics education like IMIA recommendations on education in health 
informatics [35]. The results from this study also supported the recommendation from the previous studies $[38,39]$ that Saudi universities should consider developing criteria for internship site selection. Internship selections need to focus on connecting health informatics internship program outcomes with Saudi market needs, designing effective experiential learning methods with explicit objectives and tasks and clearly defining the intern competencies and training methods. This study has a number of limitations which include participants characteristics- based on participants disclosure of their GPA and not verify from their university record. Although the invitation for the data collection is conducted through the health informatics groups in Facebook, Twitter and WhatsApp, there could be students that are not active in the social media and their opinions are not reflected in the study. However, the expansion of the sample size is required in future studies, and interviews are important with people who are responsible for health informatics internship programs in universities and hospitals to recognise the internship program from different perspectives. The gap between health informatics educational outcomes and health informatics industry demands needs to be more investigated. 


\section{Conclusion}

Internship programs are an opportunity for all three parties (Student, University, and hosting organisations), and all of them should realise the educational value provided by the experiential learning activities. Health informatics internship programs in Saudi Arabia have achieved the part of skills development, but there is still a need for collaboration between the related parties to improve the linkage between the classrooms and the practical environment. Health informatics community can define the current state of health informatics internship programs and identify the main challenges and opportunities for health informatics interns across Saudi regions. For education providers, the selection criteria of internship site, the quality of health informatics trainers and the integration between education outcomes and required competencies by employers are important aspects that need to be considered. For the health industry, the recognition of health informatics field is vital through define clearly the roles and responsibilities of health informaticians in hospitals and other health care settings. Health informatics competencies framework is crucial and can be considered as guidance for universities and health care sector in the designing process of internship programs. Finally, the role of health informatics field and health informatics profession within the Saudi health care sector shall be explicitly clarified. 


\section{Declarations:}

\subsection{Abbreviations}

\begin{tabular}{|l|l|}
\hline Acronym & Description / Definition \\
\hline HI & Health information technology \\
\hline HIT & Ministry of health \\
\hline MOH & Electronic medical record system \\
\hline EMR & Hospital information systems \\
\hline HIS & The International Medical Informatics Association \\
\hline IMIA & Clinical decision support systems \\
\hline CDSS & Electronic health record \\
\hline EHR & Enterprise resource planning system \\
\hline ERP & Saudi central board for accreditation of healthcare institutions \\
\hline CBAHI & Grade Point Average \\
\hline GPA & National Transformation Program 2020 \\
\hline NTP & Information Technology \\
\hline IT & Healthcare Information and Management Systems Society \\
\hline HIMSS &
\end{tabular}

\subsection{Ethics approval and consent to participate}

Ethics Number: 2018/416, UOW \& ISLHD Social Sciences Human Research Ethics Committee in University of Wollongong, weblink for the committee https://www.uow.edu.au/researchand-innovation/researcher-support/ethics/human-ethics/

\subsection{Consent for publication}

Not applicable

\subsection{Availability of data and material}

The datasets used and/or analysed during the current study are available from the corresponding author on reasonable request

\subsection{Competing interests}

The authors declare that they have no competing interests

6.6. Funding

Not applicable

\subsection{Authors' contributions}

KW and SA contributed to the design and implementation of the research, to the analysis of the results and to the writing of the manuscript.

\subsection{Acknowledgements}

Not applicable 


\section{References}

[1] J.M. Brittain, A.C. Norris, Delivery of health informatics education and training, Health Libr. Rev 17 (2000) 117-128. https://doi.org/10.1046/j.1365-2532.2000.00279.x.

[2] H. Chang, Recent movement on education and training in health informatics, Healthc. Inform. Res. 20 (2014) 79-80. https://doi.org/10.4258/hir.2014.20.2.79.

[3] K.R. Parker, S.S. Srinivasan, R.F. Houghton, N. Kordzadeh, K. Bozan, T. Ottaway, B. Davey, Health informatics program design and outcomes: Learning from an early offering at a mid-level university, Educ. Inform. Technol. 22 (2017) 1497-1513. https://doi.org/10.1007/s10639-016-9506-9.

[4] E.M. Borycki, J. Griffith, P. Reid, M.-H. Kuo, A.W. Kushniruk, Do electronic health records help undergraduate students develop health informatics competencies?, in: $\mathrm{C}$. Lovis, B. Séroussi, A. Hasman, L. Pape-Haugaard, O. Saka, S.K. Andersen (Eds.), e-Health - For Continuity of Care, 2014, pp. 838-842.

[5] M. Altuwaijri, Health information technology strategic planning alignment in Saudi hospitals: A historical perspective, J. Health. Inform. Dev. Ctries. 5 (2012).

[6] A.E. Stirling, G. Kerr, J. Banwell, E. MacPherson, A. Bandealy, A. Battaglia, What is an internship? An inventory and analysis of "internship" opportunities available to ontario postsecondary students, Higher Education Quality Council of Ontario, Ontario, 2014.

[7] C. Madigan, K. Johnstone, M. Cook, J. Brandon, Do student internships build capability? - What OHS graduates really think, Saf. Sci. 111 (2019) 102-110. https://doi.org/10.1016/i.ssci.2018.10.003.

[8] J.W. Gentry, What is experiential learning?, in: J.W. Gentry (Ed.), Guide to business simulation and experiential learning, Higher Education Quality Council of Ontario, East Brunswick, 1990, p. 20.

[9] R.K. Tener, M.T. Winstead, E.J. Smaglik, Experiential learning from internships in construction engineering, in: ASEE Annual Conference and Exposition: Peppers, Papers, Pueblos and Professors, ASEE, Albuquerque, 2001, pp. 4889-4920.

[10] Rhode Island's Colleges and Universities., Employer guide to structuring a successful internship program, 2018.

[11] M. True, Starting and maintaining a quality internship program, Technology Council of. Central Pennsylvania., Pittsburg, 2002.

[12] D. A. Kolb, Experiential learning: Experience as the source of learning and development, FT press, London, 2014.

[12]M.M. Robles, Executive perceptions of the top 10 soft skills needed in today's workplace, Bus. Commun. Quart. 75 (2012) 453-465.

https://doi.org/10.1177/1080569912460400. 
[13] B. Schulz, The importance of soft skills: Education beyond academic knowledge, J. Lang. Commun. (2008) 146-154.

[14] K.S. Washor, Bridging the soft-skill gap from education to employment through internships, University of Rhode Island and Rhode Island College, Providence, 2015.

[15] University of Illinois at Chicago, 5 skills needed to succeed in health informatics, 2019. https://healthinformatics.uic.edu/blog/5-skills-needed-to-succeed-in-healthinformatics/.

[16] M.J.A. Bakar, R.J. Harun, K. Yusof, I.M. Tahir, Business and accounting students' perceptions on industrial internship program, J. Edu. Voc. Res. 1 (2011) 72-79.

[17] S. Rangan, M. Natarajarathinam, How to structure an internship that is great for the intern and the manager?, in: American Society for Engineering Education Annual Conference \& Exposition, 2014.

[18] S. Rouvrais, B. Remaud, M. Saveuse, Work-based learning models in engineering curricula: insight from the French experience, Eur. J. Eng. Educ. 17 (2018) 1-14. https://doi.org/10.1080/03043797.2018.1450846.

[19] R. Muhamad, Y. Yahya, S. Shahimi, N. Mahzan, Undergraduate internship attachment in accounting: the interns perspective, Int. Educ. Stud. 2 (2009).

https://doi.org/10.5539/ies.v2n4p49.

[20] C.M. Gibson, H.I. Kwon, A. Tatachar, Impact of a low-cost simulated electronic medical record on perceptions of APPE readiness, Cur. Pharm. Teach. Learn. 11 (2019) 736-741. https://doi.org/10.1016/i.cptl.2019.03.013.

[21] N.M. George, D.M. Drahnak, D.L. Schroeder, E.D. Katrancha, Enhancing prelicensure nursing students' use of an electronic health record, Clin. Simul. Nurs. 12 (2016) 152158. https://doi.org/10.1016/i.ecns.2015.11.006.

[22] M. Choi, H. Lee, J.H. Park, Effects of using mobile device-based academic electronic medical records for clinical practicum by undergraduate nursing students: A quasiexperimental study, Nurs. Educ. Today 61 (2018) 112-119.

https://doi.org/10.1016/j.nedt.2017.11.018.

[23] M. Amatayakul, EHR versus EMR: what's in a name?, Healthc. Financ. Manage. 63 (2009) 24--25.

[24] E.M. Borycki, J. Griffith, P. Reid, A.W. Kushniruk, M.-H. Kuo, Do electronic health records help undergraduate health informatics students to develop health informatics competencies?, Stud. Health. Technol. Inform. 192 (2013) 1106-1106.

[25] A.H. Sapci, H.A. Sapci, The effectiveness of hands-on health informatics skills exercises in the multidisciplinary smart home healthcare and health informatics training laboratories, Appl Clin Inform 8 (2017) 1184-1196. https://doi.org/10.4338/ACl-201708-RA-0136. 
[26] E. Borycki, R.S. Joe, B. Armstrong, P. Bellwood, R. Campbell, Educating health professionals about the electronic health record (EHR): Removing the barriers to adoption, Knowl. Manag. E-Learn. 3 (2011) 51-62.

[27] B. Aldosari, Rates, levels, and determinants of electronic health record system adoption: a study of hospitals in Riyadh, Saudi Arabia, J. Healthc. Inform. Res. 83 (2014) 330-342. https://doi.org/10.1016/j.ijmedinf.2014.01.006.

[28] A.S. Kazley, Y.A. Ozcan, Organizational and environmental determinants of hospital EMR adoption: A national study, J. Med. Sys. 31 (2007) 375-384. https://doi.org/10.1007/s10916-007-9079-7.

[29] HIMSS Analytics, EMR adoption model, HIMSS Analytics, Chicago, 2009.

[30] D. Garets, M. Davis, Electronic medical records vs. electronic health records: yes, there is a difference. Policy White Paper, Chicago, 2006.

[31] S. Bah, T. Alanzi, Comparison of three internship training sites for an undergraduate health information management program in Saudi Arabia, Healthc. Inform. Res. 23 (2017) 233-237. https://doi.org/10.4258/hir.2017.23.3.233.

[32] H.A. Asirii, Challenges of the Health Informatics Education in the Kingdom of Saudi Arabia: What Stands in Our Way?, J. Health. Inform. Dev. Ctries. 8 (2014) 26-35.

[33] A. Alkraiji, M.S. Househ, Evaluating the role of health informatics professionals in saudi arabia: The need for collaboration, in: International Conference in Greece on Informatics, Management and Technology in Healthcare, 2014, 123-126.

[34] J. Mantas, E. Ammenwerth, G. Demiris, A. Hasman, R. Haux, W. Hersh, E. Hovenga, K.C. Lun, H. Marin, F. Martin-Sanchez, G. Wright, Recommendations of the International Medical Informatics Association (IMIA) on education in biomedical and health informatics, Method Inform Med. 49 (2010) 105-120.

https://doi.org/10.3414/ME5119.

[35] M. Alsadan, A. El Metwally, A. Ali, A. Jamal, M. Khalifa, M. Househ, Health information technology (HIT) in Arab countries: a systematic review study on HIT progress, J. Health. Inform. Dev. Ctries. 9 (2015).

[36] E. Hovenga, H. Grain, Learning, training and teaching of health \{Informatics\} and its evidence for informaticians and clinical practice, Stud. Health Technol. Inform. 222 (2016) 336-354.

[37] M.F. Alharbi, An analysis of the Saudi health-care system's readiness to change in the context of the Saudi National Health-care Plan in Vision 2030, Int. J. Health. Sci. 12 (2018) 83-87.

[38] H.I. Fallatah, Introducing inter-professional education in curricula of Saudi health science schools: An educational projection of Saudi Vision 2030, J. Taibah Univ. Med. Sci. 11 (2016) 520-525. https://doi.org/10.1016/i.jtumed.2016.10.008. 
[40] M Almalki, M Househ, M Alhefzi, Developing a Saudi health informatics competency framework: A comparative assessment, Stud. Health Technol. Inform. 264 (2019) 11011105.

7. Figure legends:

\begin{tabular}{|c|c|}
\hline \multicolumn{2}{|r|}{ EMR Adoption Model $^{\text {si }}$} \\
\hline Stage & Cumulative Capabilities \\
\hline Stage 7 & 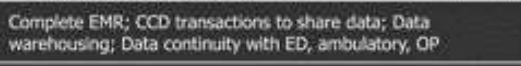 \\
\hline Stage 6 & 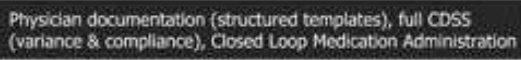 \\
\hline Stage 5 & Full compenent $\alpha$ Radidogy paCs \\
\hline Stage 4 & CROE, Cinical Decision Support (dinical protocols) \\
\hline Stage 3 & 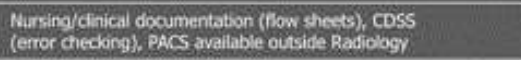 \\
\hline Stage 2 & $\begin{array}{l}\text { CDR, Controlled Medical Vocabulary, } \\
\text { COS, may have Docunent Inapging; Hif capable }\end{array}$ \\
\hline Stage 1 & Anciliaries - Lab, Rod, pharmacy - Al installed \\
\hline Stage 0 & As Three Anclaries Not instaled \\
\hline
\end{tabular}

Figure 1: EMR adoption model

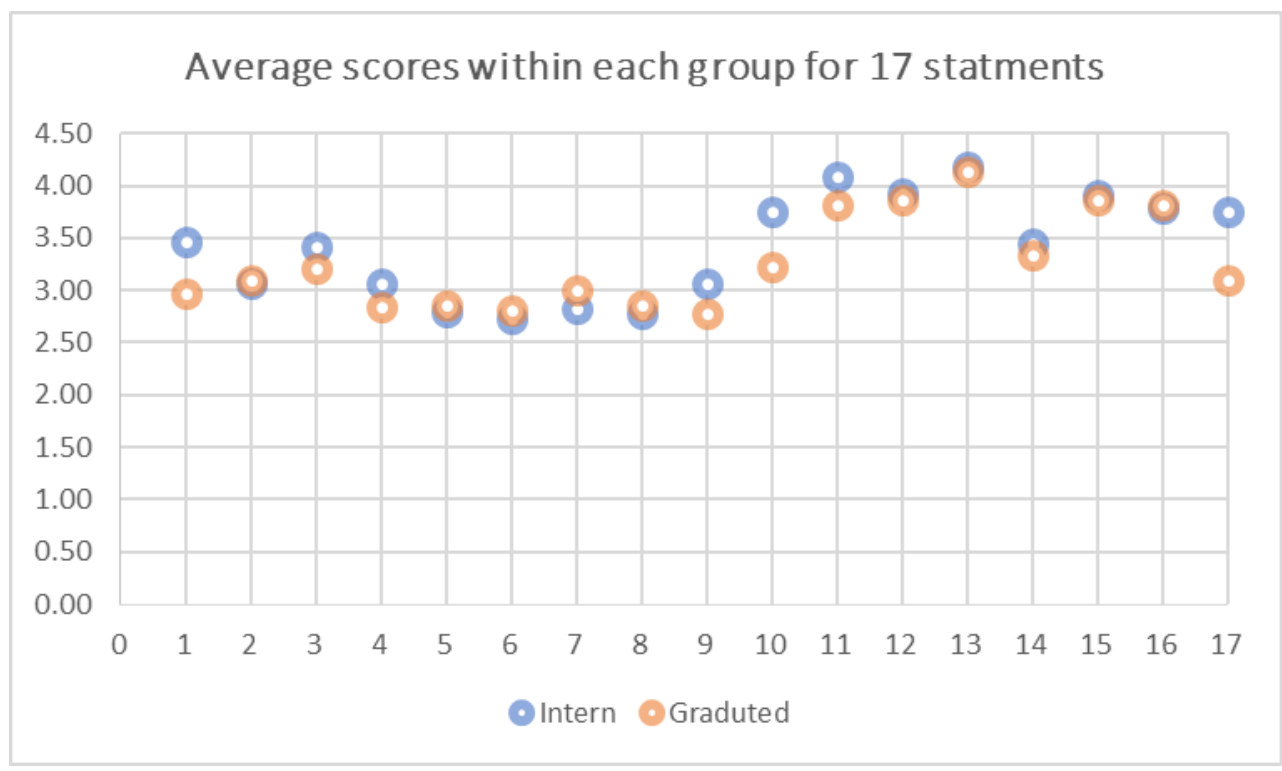

Figure 2: the mean of each group for 17 statements. 


\begin{tabular}{|c|c|}
\hline Number of participants & 89 \\
\hline \multirow{2}{*}{ Student status } & Intern student (51\%) \\
\hline & Graduated student (49\%) \\
\hline \multirow[t]{2}{*}{ Gender } & Male (46\%) \\
\hline & Female (54\%) \\
\hline \multirow[t]{4}{*}{ Internship duration } & One - Three months (44.9\%) \\
\hline & Three - Six months (14.6\%) \\
\hline & Six - Nine months (6.7\%) \\
\hline & Nine - Twelve months (33.7\%) \\
\hline \multirow[t]{6}{*}{ Department } & Medical records (35\%) \\
\hline & Information technology (15\%) \\
\hline & Health informatics (16\%) \\
\hline & Information system (3\%) \\
\hline & Clinical departments (21\%) \\
\hline & Administrative departments (10\%) \\
\hline \multirow[t]{8}{*}{ University name } & 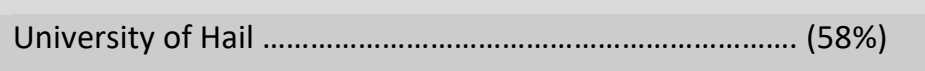 \\
\hline & 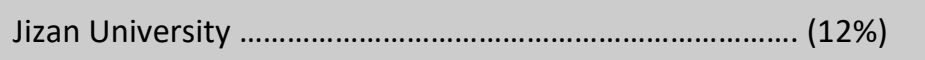 \\
\hline & AL Qassim University …...................................................... (4\%) \\
\hline & Saudi Electronic University ….............................................. (12\%) \\
\hline & Imam Abdulrahman Bin Faisal University .............................. (2\%) \\
\hline & King Saud Bin Abdelaziz University for Health Sciences. ...... (4\%) \\
\hline & 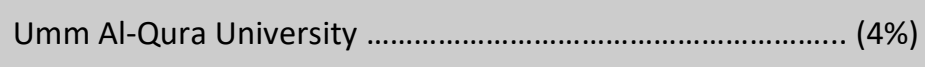 \\
\hline & Other universities \\
\hline \multirow[t]{3}{*}{ GPA } & Between \\
\hline & 1.57 and 2.70 out 4 \\
\hline & 2.71 and 3.85 out 4 \\
\hline
\end{tabular}

Table 1: Participants' characteristics. 


\begin{tabular}{|c|c|c|c|c|c|c|c|c|c|c|c|c|c|c|c|c|c|}
\hline \multirow[b]{2}{*}{ Statement } & \multicolumn{5}{|c|}{ Career } & \multicolumn{4}{|c|}{ Knowledge } & \multicolumn{5}{|l|}{ Skills } & \multicolumn{3}{|c|}{ incentives } \\
\hline & S1 & S2 & S3 & S4 & S5 & S6 & S7 & S8 & S9 & S10 & S11 & S12 & S13 & S14 & S15 & S16 & S17 \\
\hline Intern & 3.47 & 3.07 & 3.42 & 3.07 & 2.80 & 2.73 & 2.82 & 2.78 & 3.07 & 3.76 & 4.09 & 3.93 & 4.18 & 3.44 & 3.91 & 3.78 & 3.76 \\
\hline Graduated & 2.98 & 3.09 & 3.20 & 2.84 & 2.86 & 2.82 & 3.00 & 2.86 & 2.77 & 3.23 & 3.82 & 3.86 & 4.14 & 3.34 & 3.86 & 3.82 & 3.09 \\
\hline $\boldsymbol{F}$ & 3.17 & 0.01 & 0.72 & 0.71 & 0.05 & 0.09 & 0.38 & 0.10 & 1.08 & 4.09 & 1.42 & 0.08 & 0.04 & 0.14 & 0.05 & 0.03 & 6.68 \\
\hline P-value & 0.08 & 0.93 & 0.40 & 0.40 & 0.83 & 0.77 & 0.54 & 0.76 & 0.30 & 0.05 & 0.24 & 0.77 & 0.85 & 0.71 & 0.83 & 0.86 & 0.01 \\
\hline
\end{tabular}

Table 2: Anova Test-single Factor. 


\section{Appendices}

\subsection{Information about the questionnaire}

\section{Health informatics internship programs in Saudi hospitals}

This questionnaire will be used in research project for Master of Health Informatics and the questionnaire is designed to assess health informatics internship programs in Saudi Arabia. The research objectives are identifying the issues and state of internship programs for health informatics and evaluating interns' perceptions about the effectiveness of internship programs in the regional hospitals.

First part of the questionnaire is demographic information about the student status, internship site, gender, GPA (grade point average) and the department responsible for training health informatics students. The second part of the questionnaire contains seventeen statements and these statements are classified into four sections which are: career, knowledge and practical experience, skills and non-monetary incentives. Each section contains a set of statements that enable the participant to present his or her opinion about these aspects by agreement or disagreement. The purpose of these sections is to measure the impact of the health informatics internship experience on students. The third part contains three questions about the structure of internship programs and students' perceptions that can be answered with yes or no.

Please if you are Health Informatics intern student or graduated student participate in the study.

The questionnaire should take between 5 to 10 minutes to complete. Your responses are completely anonymous.

Thank you for participating in our survey. Your feedback is important.

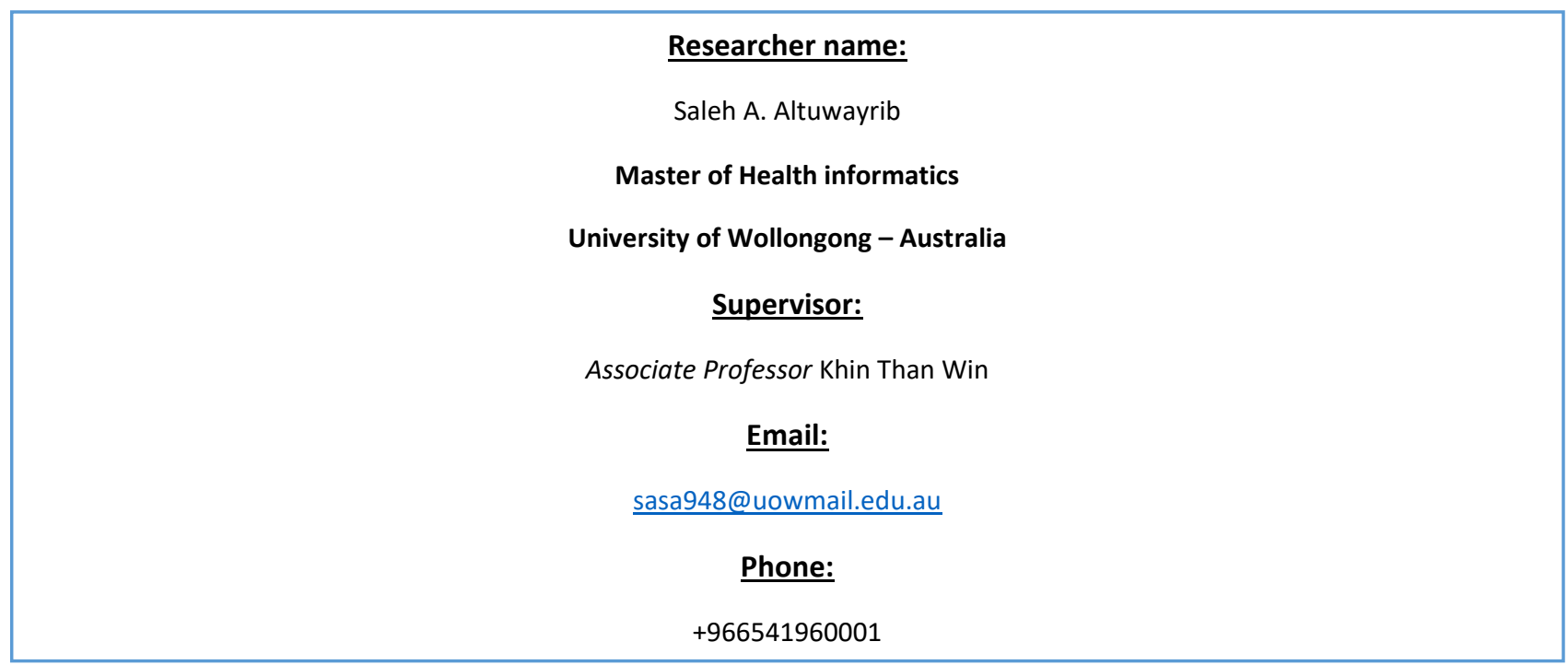


Part A: participant demographic information

\author{
Student status: \\ Intern student \\ Graduated student \\ Internship site: \\ King Khaled Hospital \\ King Salman specialist Hospital \\ Saudi Germany Hospital \\ King Fahad medical city \\ Other (* Please write the name of internship site)
}

Internship duration: (Please specify the internship period you have spent so far)

One - Three months

Three - Six months

Six - Nine months

Nine - Twelve months

Department: (Please write the name of department you work with now)

University name:

GPA:

Gender:

Male - Female 
Part B: 17 statements about career, knowledge, skills and incentives

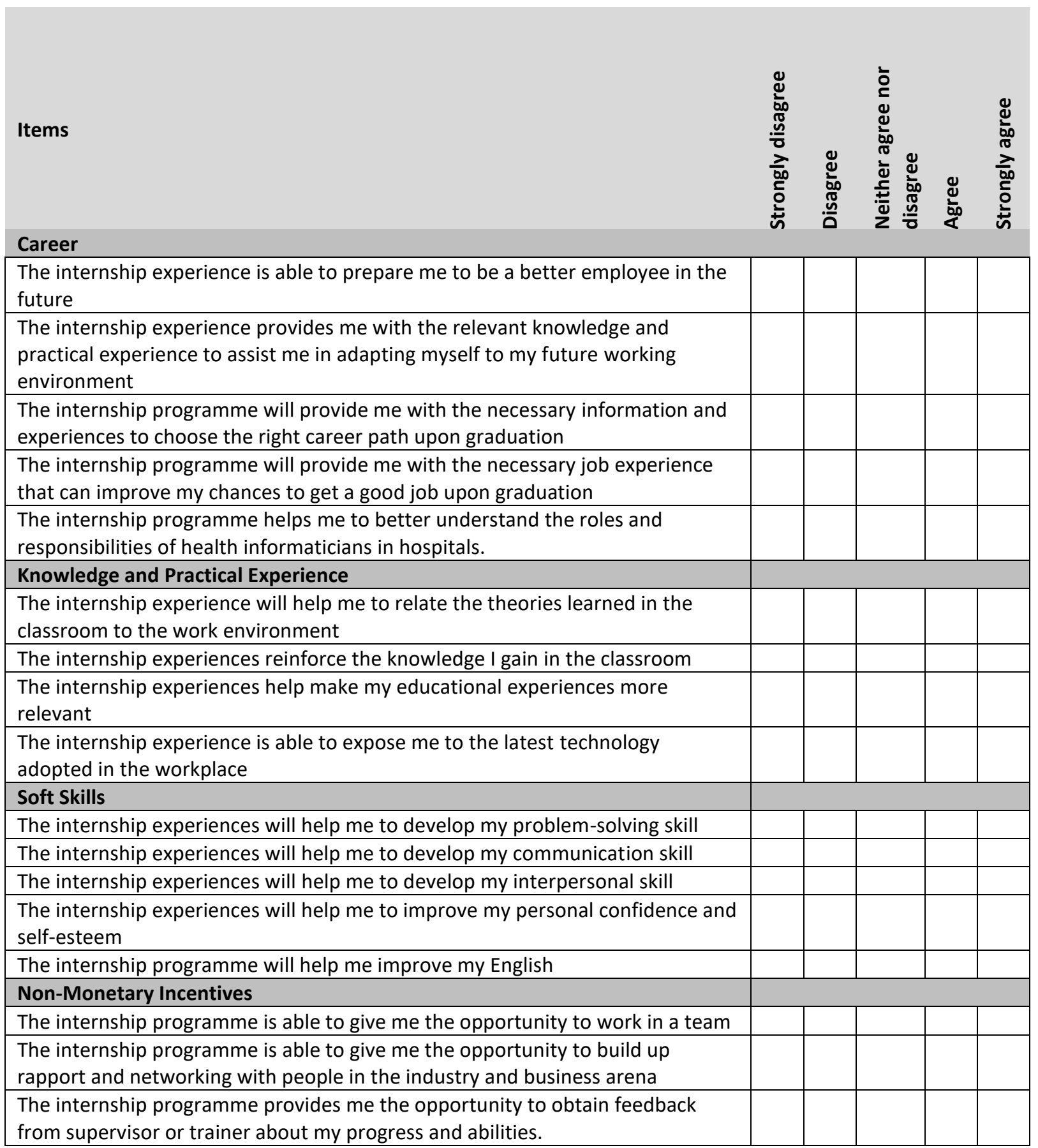


Part C: 3 closed-ended questions

In general, are you satisfied with the internship experience?

Yes/ No

Have you been provided with clear structure of internship program and explicit objectives? Yes/ No

\# Has this internship aided in clarifying your career interests and professional objectives? Yes/ No

Part D: open-ended question

What suggestions do you have for improving internship program? 


\subsection{Overall average for both graduated and intern students per statement.}

\begin{tabular}{|c|c|c|}
\hline & Career & \\
\hline Q1 & $\begin{array}{l}\text { The internship experience is able to prepare me to be } \\
\text { a better employee in the future }\end{array}$ & 3.22 \\
\hline Q2 & $\begin{array}{l}\text { The internship experience provides me with the } \\
\text { relevant knowledge and practical experience to assist } \\
\text { me in adapting myself to my future working } \\
\text { environment }\end{array}$ & 3.07 \\
\hline Q3 & $\begin{array}{l}\text { The internship programme will provide me with the } \\
\text { necessary information and experiences to choose the } \\
\text { right career path upon graduation }\end{array}$ & 3.31 \\
\hline Q4 & $\begin{array}{l}\text { The internship programme will provide me with the } \\
\text { necessary job experience that can improve my } \\
\text { chances to get a good job upon graduation }\end{array}$ & 2.95 \\
\hline \multirow[t]{2}{*}{ Q5 } & $\begin{array}{l}\text { The internship programme helps me to better } \\
\text { understand the roles and responsibilities of health } \\
\text { informaticians in hospitals. }\end{array}$ & 2.83 \\
\hline & Knowledge and practical exp. & \\
\hline Q6 & $\begin{array}{l}\text { The internship experience will help me to relate the } \\
\text { theories learned in the classroom to the work } \\
\text { environment }\end{array}$ & 2.77 \\
\hline Q7 & $\begin{array}{l}\text { The internship experiences reinforce the knowledge I } \\
\text { gain in the classroom }\end{array}$ & 2.91 \\
\hline Q8 & $\begin{array}{l}\text { The internship experiences help make my educational } \\
\text { experiences more relevant }\end{array}$ & 2.82 \\
\hline \multirow[t]{2}{*}{ Q9 } & $\begin{array}{l}\text { The internship experience is able to expose me to the } \\
\text { latest technology adopted in the work place }\end{array}$ & 2.91 \\
\hline & Skills & \\
\hline Q10 & $\begin{array}{l}\text { The internship experiences will help me to develop my } \\
\text { problem-solving skill }\end{array}$ & 3.49 \\
\hline Q11 & $\begin{array}{l}\text { The internship experiences will help me to develop my } \\
\text { communication skill }\end{array}$ & 3.95 \\
\hline Q12 & $\begin{array}{l}\text { The internship experiences will help me to develop my } \\
\text { interpersonal skill }\end{array}$ & 3.89 \\
\hline Q13 & $\begin{array}{l}\text { The internship experiences will help me to improve } \\
\text { my personal confidence and self-esteem }\end{array}$ & 4.15 \\
\hline \multirow[t]{2}{*}{ Q14 } & $\begin{array}{l}\text { The internship programme will help me improve my } \\
\text { English }\end{array}$ & 3.39 \\
\hline & Non-monetary incentives & \\
\hline Q15 & $\begin{array}{l}\text { The internship programme is able to give me the } \\
\text { opportunity to work in a team }\end{array}$ & 3.88 \\
\hline Q16 & $\begin{array}{l}\text { The internship programme is able to give me the } \\
\text { opportunity to build up rapport and networking with } \\
\text { people in the industry and business arena }\end{array}$ & 3.79 \\
\hline Q17 & $\begin{array}{l}\text { The internship programme provides me the } \\
\text { opportunity to obtain feedback from supervisor or } \\
\text { trainer about my progress and abilities. }\end{array}$ & 3.42 \\
\hline
\end{tabular}

Table 3: The average of agreement for both groups per statement 


\subsection{A list of hospital names that offer health informatics internship programs across}

the Kingdom

\begin{tabular}{|c|c|}
\hline City & \multirow[t]{2}{*}{ Hospital name } \\
\hline & \\
\hline \multirow{4}{*}{ Hail } & King Salman specialist Hospital \\
\hline & Saudi Germany Hospital \\
\hline & King Khaled Hospital \\
\hline & Maternity and Children Hospital \\
\hline Rfhaa & Rfhaa Central Hospital \\
\hline & Southern \\
\hline Abha & Asir Central Hospital \\
\hline Al Bahah & King Fahad Hospital \\
\hline \multirow[b]{4}{*}{ Jizan } & Samtah General Hospital \\
\hline & Prince Mohammed Bin Nasser Hospital \\
\hline & King Fahad Central Hospital \\
\hline & Al Amal \& Psychiatric Hospital \\
\hline \multicolumn{2}{|r|}{ Central } \\
\hline \multirow[t]{9}{*}{ Riyadh } & King Abdulaziz Medical City \\
\hline & King Fahad medical city \\
\hline & King Faisal Specialist Hospital and Research Centre \\
\hline & King Saud Medical Complex \\
\hline & Kingdom Hospital \\
\hline & Prince Sultan Cardiac Center \\
\hline & Riyadh Military Hospital \\
\hline & King Khalid University Hospital \\
\hline & National Guard Health Affairs \\
\hline Qassim & Buraydah Central Hospital \\
\hline \multicolumn{2}{|r|}{ Eastern } \\
\hline Dhahran & Johns Hopkins Aramco Healthcare \\
\hline \multirow[b]{2}{*}{ Dammam } & King Fahad Specialist Hospital \\
\hline & Dammam Medical Tower - Dammam \\
\hline Khobar & King Fahad University Hospital \\
\hline \multirow[t]{2}{*}{ Al Qatif } & Al Qatif Central Hospital \\
\hline & Anak General Hospital \\
\hline \multicolumn{2}{|r|}{ Western } \\
\hline Taif & Alhada Armed Forces Hospital \\
\hline Medina & Maternity and Children Hospital \\
\hline \multirow[t]{2}{*}{ Makkah } & Al Noor Specialist Hospital \\
\hline & Security Forces Hospital \\
\hline Jeddah & East Jeddah General Hospital \\
\hline Tabuk & New King Fahad Multi-specialty Hospital \\
\hline
\end{tabular}

Table 4: Hospitals' names across different regions 


\begin{tabular}{|c|c|c|}
\hline Hospital or Practice Name & Stage & Country \\
\hline Al Sweidi Hospital & 6 & Saudi Arabia \\
\hline King Abdulaziz Medical City-Riyadh & 6 & Saudi Arabia \\
\hline King Abdulaziz University Hospital & 6 & Saudi Arabia \\
\hline King Abdullah Medical Complex Jeddah & 6 & Saudi Arabia \\
\hline King Abdullah bin Abdulaziz University Hospital & 6 & Saudi Arabia \\
\hline King Faisal Specialist Hospital \& Research Centre - Jeddah & 6 & Saudi Arabia \\
\hline King Faisal Specialist Hospital \& Research Centre - Riyadh & 6 & Saudi Arabia \\
\hline King Khaled Eye Specialist Hospital & 7 & Saudi Arabia \\
\hline King Khalid University Hospital & 6 & Saudi Arabia \\
\hline Mouwasat Hospital in Dammam & 6 & Saudi Arabia \\
\hline Mouwasat Hospital in Qatif & 6 & Saudi Arabia \\
\hline Mouwasat Hospital in Riyadh & 6 & Saudi Arabia \\
\hline Security Forces Hospital - Makkah & 6 & Saudi Arabia \\
\hline Security Forces Hospital Program (Dammam) & 6 & Saudi Arabia \\
\hline Sultan Bin Abdulaziz Humanitarian City & 6 & Saudi Arabia \\
\hline
\end{tabular}

Table 5: a list of Saudi hospitals rewarded with Stage 6\&7 HIMSS Adoption Model 
Dear Mr Altuwayrib,

I am pleased to advise that the application detailed below has been approved.

Ethics Number: 2018/416

Approval Date: 23/10/2018

Expiry Date: 22/10/2019

Project Title: Internship programs for Undergraduate Health Informatics students in Saudi Arabia

Researcher: Altuwayrib Saleh

Documents Approved:

Initial Application rec. 18/10/2018

Response to Review rec. 18/10/2018

Consent Form rec. 10/09/2018

Participant Information Sheet V2, 18/10/2018

Invitation Script rec. 10/09/2018

Questionnaire rec. 10/09/2018

Internship Information rec. 10/09/2018

Sites:

\begin{tabular}{|l|l|}
\hline Site & Principal Investigator for Site \\
\hline Survey Monkey & Saleh Altuwayrib \\
\hline
\end{tabular}

The HREC has reviewed the research proposal for compliance with the National Statement on Ethical Conduct in Human Research and approval of this project is conditional upon your continuing compliance with this document. Compliance is monitored through progress reports; the HREC may also undertake physical monitoring of research.

Approval is granted for a twelve-month period; extension of this approval will be considered on receipt of a progress report prior to the expiry date. Extension of approval requires:

- The submission of an annual progress report and a final report on completion of your project.

- Approval by the HREC of any proposed changes to the protocol or investigators.

- Immediate report of serious or unexpected adverse effects on participants.

- Immediate report of unforeseen events that might affect the continued acceptability of the project.

Yours sincerely,

\section{Emma Barkus}

Associate Professor Emma Barkus,

Chair, UOW \& ISLHD Social Sciences Human Research Ethics Committee 